4 Pierce JP, Gilpin EA, Emery SL, Farkas AJ, Zhu SH, Choi WS, et al. Tobacco control in California: who's winning the war? An evaluation of the tobacco control program, 1989-1996. La Jolla, CA: University of California, San Diego, 1998. http://ssdc.ucsd.edu/tobacco/reports/

5 Borland R, Mullins R, Trotter L, White V. Trends in environmental tobacco smoke restrictions in the home in Victoria, Australia. Tobacco Control 1999:8:266-71.

6 Wasserman J, Manning WG, Newhouse JP, Winkler JD. The effects of excise taxes and regulations on cigarette smoking. $J$ Health Econ 1991;10:43-64.

7 Chaloupka FJ, Grossman M. Price, tobacco control policies and youth smoking. Cambridge, MA: National Bureau of Economic Research, 1996. (Working papers No 5740.) http://papers.nber.org/papers/W5740

8 Tauras JA, Chaloupka FJ. Clean indoor air, and cigarette smoking: evidence from the longitudinal data for young adults. Cambridge, MA: National Bureau of Economic Research, 1999. (Working paper No 6937.) http:// papers.nber.org/papers/W6937

9 Biener L, Cullen D, Xiao Z, Hammond SK. Household smoking restrictions and adolescent's exposure to environmental tobacco smoke. Prew Med 1997;26:358-63.

10 Flay B. Youth tobacco use: risks, patterns and control. In: CT Orleans, J Slade, eds. Nicotine addiction:principles and management. New York: Oxford University Press, 1993:365-84.

11 Pentz MA, Dwyer JH, MacKinnon DP, Flay BR, Hansen WB, Wang EY, et al. A multicommunity trial for primary prevention of adolescent drug abuse. JAMA 1989;261:3259-66.

12 Charlton A, While D. Smoking prevalence among 16-19 year olds related to staff and student smoking policies in sixth forms and further education. Health Educ J 1994;53:191-215.

13 Pentz MA, Sussman S, Newman T. The conflict between least harm and no-use tobacco policy for youth: ethical and policy implications. Addiction 1997:92:1165-73.

14 Pierce JP, Choi WS, Gilpin EA, Farkas AJ, Merritt RK. Validation of susceptibility as a predictor of which adolescents take up smoking in the United States. Health Psychol 1996;15:355-61.

15 Office on Smoking and Health. State tobacco activities tracking and evalua tion system. Atlanta, GA: Centers for Disease Control and Prevention,
Department of Health and Human Services. www2.cdc.gov/nccdphp/ osh/state/index.htm (accessed 23 June 2000)

16 Hedeker D, Gibbons RD. MIXOR/MIXREG: programs for mixed-effects linear regression and mixed-effects logistic regression with ordinal outcomes. www.uic.edu/ hedeker/mixreg.html (accessed 23 June 2000)

17 Hedeker D, Mermelstein RJ. A multilevel thresholds of change model for analysis of stages of change data. Multivariate Behavioral Res 1998;33:427-55.

18 Wakefield M, Chaloupka F, Kaufman N, Orleans CT, Ruel E. Do smoking restrictions at home, at school and in public places, influence youth smoking? Chicago, IL: University of Illinois, 2000. (ImpacTeen working paper series No 3.) (http://www.uic.edu/ hedeker/mixreg.html)

19 Emont SL, Choi WS, Novotny TE, Giovino GA. Clean indoor air legislation, taxation and smoking behavior in the United States: an ecological analysis. Tobacco Control 1992;2:13-7.

20 Hocking B, Borland R, Owen N. A total ban is acceptable and effective. J Occup Med 1991;33:163-7.

21 Wakefield M, Roberts L, Owen N. Trends in prevalence and acceptance of workplace smoking bans among indoor workers in South Australia. Tobacco Control 1996:5.205-8.

22 Hyland A, Cummings KM, Wilson MP. Compliance with the New York City Smoke-Free Air Act. J Public Health Manag Pract 1999;5:22-7.

23 Jacobsen PD, Wasserman J. The implementation and enforcement of tobacco control laws: policy implications for activists and the industry. $J$ Health Polit Policy Law 1999:24:567-98.

24 Aaro L, Hauknes A, Berglund E. Smoking among Norwegian schoolchildren 1975-1980. 2. The influence of the social environment. Scand J Psychol 1981;22:297-309.

25 Eiser JR, Morgan M, Gammage P, Gray E. Adolescent smoking: attitudes, norms and parental influence. Br J Soc Psychol 1989;28:193-202.

26 Mermelstein R and the Tobacco Control Network Writing Group. Explanations of ethnic and gender differences in youth smoking: a multisite, qualitative investigation. Nicotine Tobacco Res 1999;1:S91-8.

(Accepted 9 June 2000)

\title{
Effect of counselling mothers on their children's exposure to environmental tobacco smoke: randomised controlled trial
}

Melbourne F Hovell, Joy M Zakarian, Georg E Matt, C Richard Hofstetter, J Thomas Bernert, James Pirkle

\begin{abstract}
Objective To test the efficacy of behavioural counselling for smoking mothers in reducing young children's exposure to environmental tobacco smoke. Design Randomised double blind controlled trial. Setting Low income homes in San Diego county, California.

Participants 108 ethnically diverse mothers who exposed their children (aged $<4$ years) to tobacco smoke in the home.

Intervention Mothers were given seven counselling sessions over three months.

Main outcome measures Children's reported exposure to environmental tobacco smoke from mothers in the home and from all sources; children's cotinine concentrations in urine.

Results Mothers' reports of children's exposure to their smoke in the home declined in the counselled group from 27.30 cigarettes/week at baseline, to 4.47 at three months, to 3.66 at 12 months and in the controls from 24.56 , to 12.08 , to 8.38 . The differences between the groups by time were significant $(\mathrm{P}=0.002)$. Reported exposure to smoke from all sources showed similar declines, with significant differences between groups by time $(P=0.008)$. At 12
\end{abstract}

months, the reported exposure in the counselled group was $41.2 \%$ that of controls for mothers' smoke (95\% confidence interval $34.2 \%$ to $48.3 \%$ ) and was $45.7 \%$ (38.4\% to $53.0 \%)$ that of controls for all sources of smoke. Children's mean urine cotinine concentrations decreased slightly in the counselled group from $10.93 \mathrm{ng} / \mathrm{ml}$ at baseline to $10.47 \mathrm{ng} / \mathrm{ml}$ at 12 months but increased in the controls from 9.43 $\mathrm{ng} / \mathrm{ml}$ to $17.47 \mathrm{ng} / \mathrm{ml}$ (differences between groups by time $\mathrm{P}=0.008$ ). At 12 months the cotinine concentration in the counselled group was $55.6 \%$ $(48.2 \%$ to $63.0 \%)$ that of controls.

Conclusions Counselling was effective in reducing children's exposure to environmental tobacco smoke. Similar counselling in medical and social services might protect millions of children from environmental tobacco smoke in their homes.

\section{Introduction}

The World Health Organization has estimated that the health of almost half of the world's children is threatened by exposure to environmental tobacco smoke. ${ }^{1}$ In the United States the prevalence of US children living in homes with a smoker has been estimated to be $43 \%$, with state specific estimates of exposure in
USA

Melbourne F Hovell professor

Joy M Zakarian

senior research

associate

Georg E Matt

professor

C Richard

Hofstetter

professor

continued over

BMJ 2000;321:337-42 
Centers for Disease Control and Prevention,

National Center for Environmental

Health, Division of Laboratory

Sciences, Atlanta, GA 30341-3724,

USA

J Thomas Bernert supervisory research chemist

James Pirkle

assistant director for science

Correspondence to: M F Hovell behepi@rohan. sdsu.edu the home ranging from $12 \%$ to $34 \%^{2}$; nationally, about 15 million US children and adolescents are exposed. ${ }^{3}$ Similarly, about $43 \%$ of Australian children, ${ }^{4} 33 \%$ of Canadian children, ${ }^{5}$ and $41 \%$ of British children are exposed to environmental tobacco smoke. ${ }^{6}$ Exposure increases children's risk of respiratory tract infections, otitis media, asthma, and the sudden infant death syndrome ${ }^{7-9}$ The costs to children's medical care from exposure were $\$ 703 \mathrm{~m}-\$ 897 \mathrm{~m}(£ 439 \mathrm{~m}-£ 561 \mathrm{~m})$ in the United States, $\$ 239.5 \mathrm{~m}(£ 150 \mathrm{~m})$ in Canada, and $\$ 267 \mathrm{~m}\left(£ 167 \mathrm{~m}\right.$ ) in Great Britain (in 1997 prices). ${ }^{10}$

Two trials reported significant decreases in children's exposure to environmental tobacco smoke after counselling of parents. Greenberg et al decreased children's reported exposure, but infants' urine cotinine concentrations increased. ${ }^{11}$ Hovell and colleagues found similar reductions in reported exposure, which were sustained over two years, but did not measure cotinine concentrations..$^{13}$ We extended our earlier research by measurement of cotinine concentrations and by testing counselling (in person and by telephone) with high risk, ethnically diverse, and low income families recruited from the US supplemental nutrition programme for women, infants, and children. We hypothesised that counselling would decrease children's exposure, decrease mothers' smoking, and increase rates of stopping smoking.

\section{Participants and methods}

\section{Protocol}

\section{Inclusion criteria}

We included English and Spanish speaking mothers who smoked at least two cigarettes a day and exposed their child (aged $<4$ years) to the smoke from at least one cigarette a day. We excluded women who were currently breast feeding, to avoid confounded cotinine analyses, ${ }^{14}{ }^{15}$ and women who did not have a telephone, to ensure exposure to the intervention.

\section{Recruitment}

Nine months' screening at sites of the supplemental nutrition programme for women, infants, and children identified 1147 possibly eligible families. Of these, we contacted 832: 162 (19.5\%) qualified and were offered financial incentives $(\$ 60-\$ 90)$ to participate. We enrolled the first 108 women who signed informed consent forms, an adequate sample size based on previous research. ${ }^{12}$ After we had taken baseline measures, we randomly assigned the families to counselling or control conditions.

\section{Counselled group}

Counselled mothers were told that quitting smoking was not required. They were given seven individualised counselling sessions (three in person and four by telephone) during three months. Counselling was based on shaping procedures. ${ }^{16}$ The mean duration of sessions ranged from 12.6 to 28.0 minutes. Graduate students with 20 hours of training and weekly supervision by case review provided the counselling.

At the first session, mothers set long term goals for reducing children's exposure to environmental tobacco smoke and signed contracts. Counsellors explained the shaping process (in which complex smoking practices were gradually altered to reduce exposure to the child) and assisted mothers in writing fortnightly objectives that resembled medical prescriptions. Between sessions, mothers recorded their smoking and their child's exposure on pictorial charts. Mothers were provided with "No smoking" signs and stickers to serve as cues for reducing their child's exposure. In subsequent sessions, counsellors reviewed progress and negotiated possible solutions to barriers to reducing children's exposure. New objectives and strategies were set. Contingencies included praise from counsellors and low cost "self rewards." In the last session mothers were helped to write final goals and objectives for maintaining low exposure or for further decreasing exposure. Details about the counselling programme are published elsewhere. ${ }^{17}$

\section{Control group}

Mothers received the usual nutritional counselling of the supplemental nutrition programme and brief advice to quit smoking and not expose their children to environmental tobacco smoke.

\section{Measures of exposure to environmental tobacco smoke}

\section{Mothers'reports}

Interviews were conducted at baseline, at three months (after counselling), and at six and 12 months. The baseline interview was conducted in person in the mothers' homes, and follow up interviews were by telephone. The mean length of interviews was 57.2 (SD 15.8) minutes. Content included information on mothers' demographics and tobacco use and their child's exposure to environmental tobacco smoke.

Mothers reported their smoking and their child's exposure on typical work days and non-work days during the past seven days. They reported children's exposure to smoke from others living in and visiting the home, and from all smokers outside of the home. We measured exposure as the number of cigarettes smoked while the child was in the same room and calculated children's weekly exposure to mothers' cigarettes in the home and to all cigarettes. Acceptable testretest reliability and validity in relation to cotinine and nicotine assays are reported elsewhere. ${ }^{18} 19$

Children's urine cotinine concentrations

Urine samples (collected at baseline and three and 12 months) were analysed for cotinine (a metabolite of nicotine and recommended biomarker) ${ }^{20}$ at the Centers for Disease Control and Prevention by means of isotope dilution liquid chromatography and tandem mass spectrometry with a limit of detection of $<50$ parts per trillion. We obtained samples from children who were not toilet trained by placing two sterile $15 \mathrm{~cm}$ cotton rolls in diapers and removing these when they were wet. The cotton rolls were packed into a sterile 20 $\mathrm{ml}$ syringe (without needle), and the urine was expressed into a $5 \mathrm{ml}$ vial. Previous research showed that cotton rolls do not alter the cotinine concentration. ${ }^{21}$ Samples from toilet trained children were collected with a standard urine collection cup. Samples were frozen at $-29^{\circ} \mathrm{C}$ and packed in dry ice for shipping. The laboratory was blind to subjects' identity and group assignment. 
Mothers'saliva cotinine concentrations

Mothers' saliva was obtained at each interview with Episcreen collection devices (Epitope, Beaverton, OR) and stored frozen at $-29^{\circ} \mathrm{C}$ until laboratory analysis by enzyme linked immunoassay (STC, Bethlehem, PA). The laboratory was blind to subjects' identity and group assignment. Mothers who reported stopping smoking were tested and cessation confirmed by cotinine concentrations $<30 \mathrm{ng} / \mathrm{ml}$.

\section{Nicotine monitors}

We conducted nicotine monitoring to provide objective validation of mothers' reported levels of smoking and to enhance reporting accuracy. ${ }^{22}$ Inactive monitors were placed in three rooms per household where children's greatest exposure to environmental tobacco smoke was reported. These were used to sensitise the mothers to possible confirmation of their reports of exposure. One week before the three month interview, we placed an active monitor in the room of greatest exposure for a randomly selected half of the families. The monitor was a $37 \mathrm{~mm}$ diameter cassette containing a Teflon coated glass fibre filter (Emfab TX 40h120WW, Pallflex, Putnam, CT) saturated with 4\% sodium bisulphate and 5\% ethanol and dried. Gas chromatography was used to assess nicotine levels. ${ }^{23}{ }^{24}$ Assays confirmed the validity of mothers' reports. ${ }^{19}$

\section{Assignment and masking}

Random numbers were used to stratify assignment by three ethnic groups. After the baseline measures, assistants opened an envelope to reveal assignments. Measurement assistants were blind to group assignment. Control families were unaware of counselling procedures, and investigators were blind to results until all data were collected.

\section{Statistical analyses}

Analyses were based on intention to treat. We adjusted dependent variables by logarithmic or square root transformation to reduce skewness and present geometric and untransformed means. Differential rate of change in reported exposure and cotinine estimates of exposure relied on analyses of repeated measures over time. Estimated power to detect differential change between groups exceeded 0.80 for all dependent variables. We analysed the effects of counselling using the generalised estimating equations approach, with linear components of time as "within subjects" factors and the interaction as a "between subjects" factor (SAS version 6.12). ${ }^{25}$ Modelling procedures based on generalised estimating equations are superior to models based on analysis of variance in that they do not require repeated measures to be equally spaced from one another and they retain cases with missing data at one or more times. We first calculated differential change from baseline to end of follow up and then repeated this for baseline to three months (counselling effect) and from three months to end of follow up (maintenance effect).

\section{Results}

\section{Participant flow and follow up}

Figure 1 shows the number of mothers enrolled through completion of measures. Forty nine (92\%) of

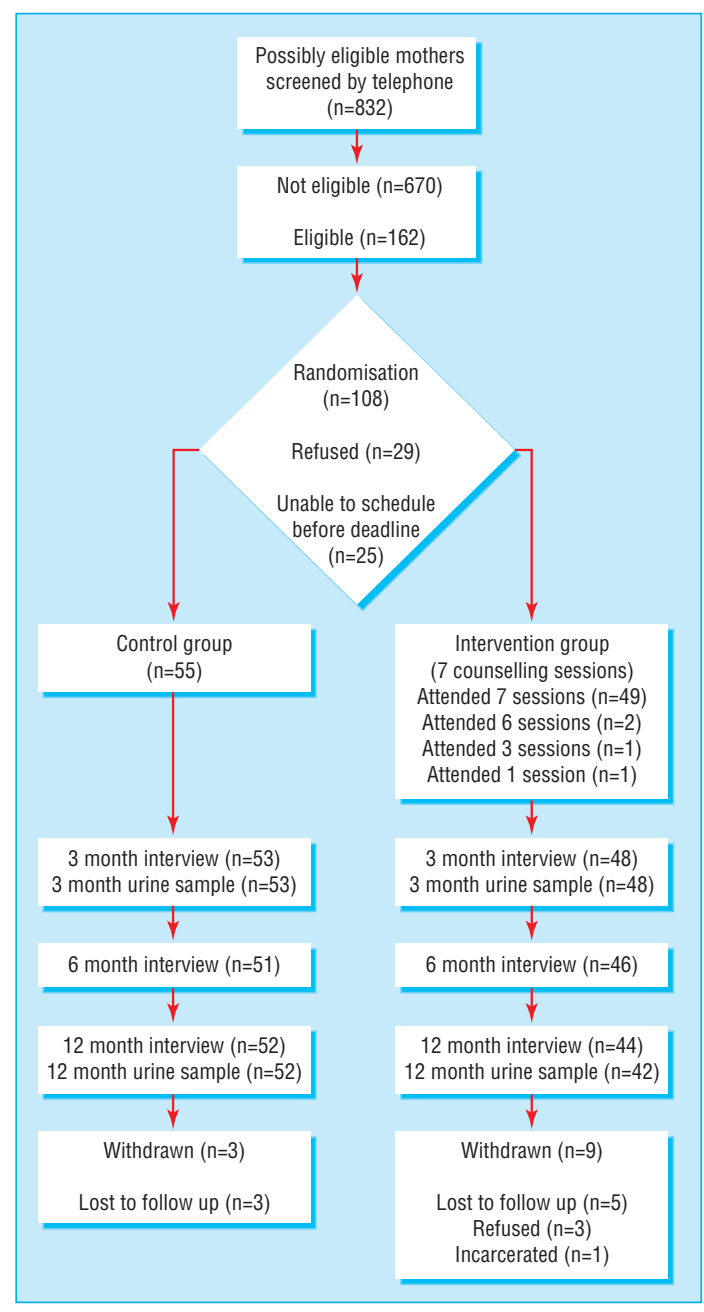

Fig 1 Flow of participants through trial

the mothers assigned to the counselling group completed all seven counselling sessions.

\section{Participants}

Table 1 shows the demographic characteristics of the mothers and children. Families were white, black, or Hispanic and had low income with limited education.

\section{Sampling and success of random assignment}

The two groups were well matched in their demographic and dependent variables, suggesting successful random assignment.

\section{Analyses}

Reported exposure

Figure 2 shows that in both groups the children's reported exposure to their mothers' tobacco smoke in the home declined steeply from baseline to three months (end of counselling) and then only slightly during follow up. Our analyses of repeated measures showed significant differences between groups by time $(\mathrm{P}=0.002)$, indicating that exposure declined more for the counselled group than for the control group. Analyses of changes from baseline to three months also showed significant differences between groups by time $(\mathrm{P}=0.011)$. From three months to 12 months, the difference between the two groups remained signifi- 


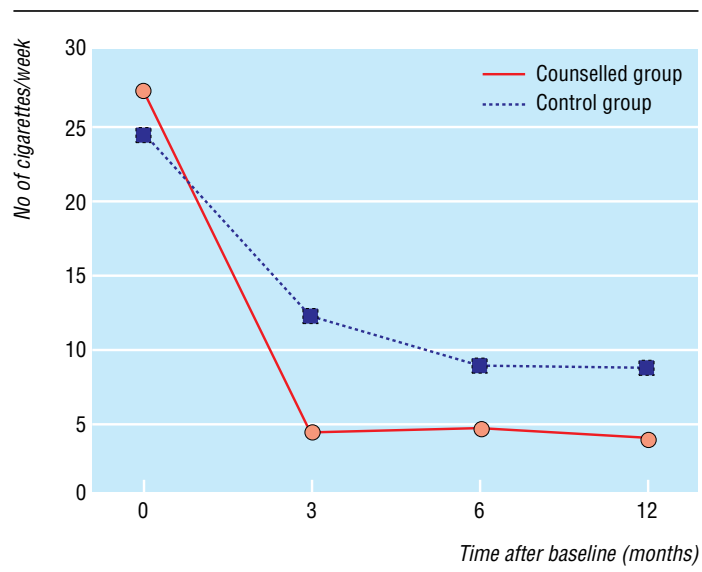

Fig 2 Children's reported exposure to mothers' cigarettes in the home (No of cigarettes per week) in families with a young child ( $<4$ years old) and a mother who smoked who received either three months of counselling or standard advice to reduce smoking in the presence of the child. Values are geometric means

cant $(\mathrm{P}=0.017)$, but neither showed any significant change over time, suggesting that the counselling effect was maintained but that no later improvement occurred. Student's $t$ tests showed a significant cross sectional difference between the groups at three months only $(t(99)=-2.74(95 \%$ confidence interval -1.503 to -0.240$) ; \mathrm{P}=0.007)$. Thus, the effects of counselling were obtained by three months and sustained through follow up. Table 2 shows the geometric means for children's exposure to environmental tobacco smoke at baseline, three months, and 12 months.

Children's reported total exposure to environmental tobacco smoke followed a similar pattern (table 2), with the counselled group showing a significantly

Table 1 Baseline characteristics of families with a young child ( $<4$ years old) and a mother who smoked who received either three months of counselling or standard advice to reduce smoking in the presence of the child. Values are numbers (percentages) unless stated otherwise

\begin{tabular}{|c|c|c|}
\hline Variable & $\begin{array}{c}\text { Counselled families } \\
\qquad(\mathrm{n}=53)\end{array}$ & $\begin{array}{l}\text { Control families } \\
\qquad(\mathrm{n}=55)\end{array}$ \\
\hline \multicolumn{3}{|l|}{ Ethnic group: } \\
\hline Black & $11(21)$ & $12(22)$ \\
\hline Hispanic & $14(26)$ & $16(29)$ \\
\hline White & $25(47)$ & $26(47)$ \\
\hline Other & $3(6)$ & $1(2)$ \\
\hline Children's sex (girls) & $31(58)$ & $26(47)$ \\
\hline Single parent families & $23(43)$ & $27(49)$ \\
\hline Employed mothers & $8(15)$ & $5(9)$ \\
\hline \multicolumn{3}{|l|}{ Mothers' education: } \\
\hline Less than high school or GED* & $22(42)$ & $20(36)$ \\
\hline High school or GED* & $14(26)$ & $13(24)$ \\
\hline Trade school & $4(8)$ & $4(7)$ \\
\hline Some college & $12(23)$ & $16(29)$ \\
\hline College graduate & $1(2)$ & $2(4)$ \\
\hline \multicolumn{3}{|l|}{ Mean (SD) age: } \\
\hline Mothers' (years) & $28.5(6.6)$ & $29.0(6.9)$ \\
\hline Children's (months) & $14.1(7.0)$ & $14.3(6.9)$ \\
\hline $\begin{array}{l}\text { Mean (SD) No of times mothers had stopped smoking } \\
\text { for } 24 \text { hours }\end{array}$ & $11.6(25.0)$ & $19.4(48.0)$ \\
\hline Mothers' mean No of cigarettes smoked/day & $12.6 \dagger$ & $12.2 \dagger$ \\
\hline
\end{tabular}

*GED=Generalised equivalency degree.

tMeans are squared estimates of means adjusted by square root transformation and so do not include standard deviations. These estimates provide an indication of the levels in clinically meaningful units. greater decline $(\mathrm{P}<0.008)$. Both groups showed significant declines from baseline to three months $(\mathrm{P}<0.001)$. From three months to 12 months, the difference between the two groups remained significant $(\mathrm{P}=0.043)$, but neither showed any significant change in exposure over time. Student's $t$ tests showed significant differences between the two groups at three months $(t(94)=-2.30(-1.244$ to -0.092$) ; \mathrm{P}=0.024)$ and 12 months $(t(91)=-2.10(-1.430$ to -0.039$)$; $\mathrm{P}=0.039$ ), suggesting that counselling had an effect and that this was maintained.

Children's urine cotinine concentration

Figure 3 shows that children's cotinine concentrations increased from baseline to three months in both groups but that the concentration then declined slightly in the counselled group whereas it continued to increase in the control group. Our analyses of repeated measures showed significant differences between groups by time $(\mathrm{P}=0.008)$. Student's $t$ tests showed significant differences between the two groups only at 12 months $(t(90)=-2.05(-0.948$ to -0.015$)$; $\mathrm{P}=0.043)$. These results suggested a prevention effect that lasted through follow up.

\section{Mothers'saliva cotinine concentration}

From baseline to three months, the mothers' cotinine concentrations increased significantly in both groupsfrom $75.8 \mathrm{ng} / \mathrm{ml}$ to $91.2 \mathrm{ng} / \mathrm{ml}$ for counselled women and from $76.9 \mathrm{ng} / \mathrm{ml}$ to $89.7 \mathrm{ng} / \mathrm{ml}$ for controls $(\mathrm{P}<0.001)$. During follow up, counselled mothers' cotinine concentrations decreased to $80.6 \mathrm{ng} / \mathrm{ml}$ at 12 months, while those of the controls increased to 112.9 $\mathrm{ng} / \mathrm{ml}$. This difference between groups by time neared significance $(\mathrm{P}=0.06)$, suggesting a possible decrease in the relative level of smoking for counselled mothers compared with controls. There were no significant differences in the numbers of mothers who stopped smoking (six in the counselling group and four in the control group).

\section{Discussion}

This is the first study to show therapeutic benefits of counselling mothers on their children's exposure to environmental tobacco smoke based on cotinine concentrations. In the counselled group the children's cotinine concentrations decreased slightly (4\%) by 12 months, whereas those in the control group increased substantially $(85 \%)$, suggesting that counselling prevented an increase in exposure to environmental tobacco smoke. Reported exposure to environmental tobacco smoke decreased more after counselling and was sustained for nine months, suggesting maintenance of effects consistent with our previous findings. ${ }^{13}$

Our present results extend earlier work by showing the efficacy of counselling delivered in part by telephone to women receiving services from the supplemental nutrition programme for women, infants, and children. The successful decrease (or prevention of increase) in children's exposure to environmental tobacco smoke in this low income, racially and ethnically diverse, high risk population suggests that counselling is generalisable, as does the similarity of our results to those from earlier studies. ${ }^{11-13}$ Such counselling in medical and social services might 
Table 2 Measures of children's exposure to environmental tobacco smoke in families with a young child ( $<4$ years old) and a mother who smoked who received either three months of counselling or standard advice to reduce smoking in the presence of the child. Values are geometric means (interquartile ranges) unless stated otherwise

\begin{tabular}{|c|c|c|c|}
\hline \multirow[b]{2}{*}{ Variable } & \multicolumn{3}{|c|}{ Time } \\
\hline & Baseline & 3 months (after counselling) & 12 months \\
\hline \multicolumn{4}{|c|}{ Reported exposure to environmental tobacco smoke (№ of cigarettes/week) } \\
\hline \multicolumn{4}{|l|}{ Exposure from mothers in home: } \\
\hline Counselled families & $27.30(32.91)$ & $4.47(26.11)$ & $3.66(28.08)$ \\
\hline Control families & $24.56(31.03)$ & $12.08(33.09)$ & 8.38 (45.99) \\
\hline Relative value for counselled group $v$ controls $(\%(95 \% \mathrm{Cl}))^{*}$ & & 32.8 (26.3 to 39.3$)$ & $41.2(34.2$ to 48.3$)$ \\
\hline \multicolumn{4}{|l|}{ Total environmental exposure: } \\
\hline Counselled families & $51.30(73.43)$ & $12.99(42.94)$ & $8.60(44.15)$ \\
\hline Control families & $50.68(63.68)$ & $26.28(59.79)$ & $19.23(66.91)$ \\
\hline Relative value for counselled group $v$ controls $(\%(95 \% \mathrm{Cl}))^{*}$ & & 50.0 (42.8 to 57.2$)$ & 45.7 (38.4 to 53.0$)$ \\
\hline \multicolumn{4}{|l|}{ Urine cotinine concentration $(\mathrm{ng} / \mathrm{ml})$} \\
\hline Counselled families & $10.93(17.29)$ & $12.65(12.12)$ & $10.47(24.28)$ \\
\hline Control families & 9.43 (13.28) & $13.88(18.00)$ & 17.47 (21.61) \\
\hline Relative value for counselled group $v$ controls $(\%(95 \% \mathrm{Cl}))^{*}$ & & $84.2(79.0$ to 89.4$)$ & 55.6 (48.2 to 63.0$)$ \\
\hline
\end{tabular}

*Means were adjusted for baseline levels to calculate relative values.

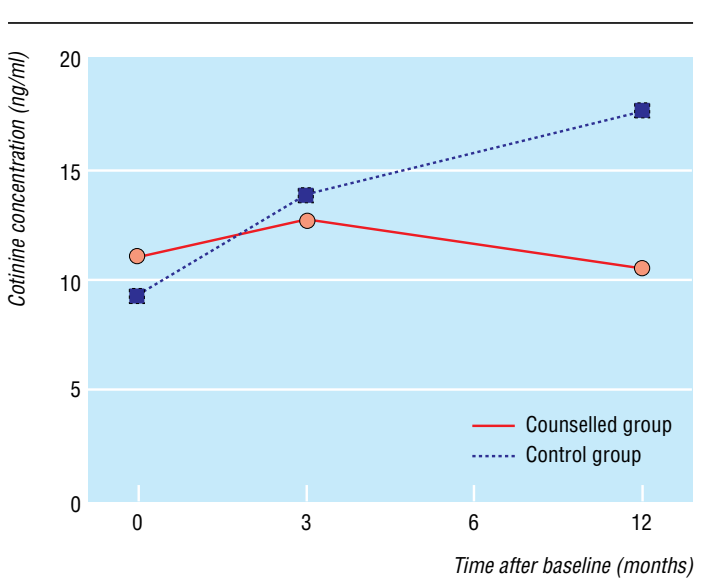

Fig 3 Children's urine cotinine concentrations $(\mathrm{ng} / \mathrm{ml})$ in families with a young child $(<4$ years old) and a mother who smoked who received either three months of counselling or standard advice to reduce smoking in the presence of the child. Values are geometric means

protect millions of children from exposure to environmental tobacco smoke.

Smoking decreased slightly among counselled mothers but increased by half among controls. Counselling may have prevented an increase in mothers' smoking over time, although it did not result in more mothers quitting. Increased smoking among the controls probably contributed to their children's increased cotinine concentrations.

Parental reports of reducing their children's exposure could reflect the parents smoking in a different room but still close enough for the child to inhale smoke. Similarly, as children begin walking, they may be exposed to nicotine from dust on carpets and furniture. This would not be easily monitored or reported by parents and might account for the control mothers reporting decreased exposure to environmental tobacco smoke whereas their children had increased cotinine concentrations. Additional research is needed to determine the source of increasing cotinine concentrations in control children.

\section{Conclusions}

Both mothers' reports and cotinine analyses confirmed the benefits of counselling on children's exposure to environmental tobacco smoke. The most conservative interpretation of the results suggests that counselling prevented an increase in exposure to environmental tobacco smoke. Future studies should be directed to interventions that combine formal counselling for quitting smoking with counselling for reducing children's exposure to environmental tobacco smoke. Future studies should also extend follow up to assess how long the effects of counselling are maintained and the developmental trends in exposure to environmental tobacco smoke. These results set the stage for research to determine the effects of reducing exposure to environmental tobacco smoke on morbidity and mortality.

We thank the following investigators for their assistance during the conduct of this trial: Chris Ake, Department of Family and

\section{What is already known on this topic}

The World Health Organization has estimated that the health of almost half of the world's children is threatened by exposure to environmental tobacco smoke

Two trials reported significant decreases in children's exposure to environmental tobacco smoke after counselling of mothers, but neither provided an objective outcome measure of efficacy

\section{What this study adds}

A randomised trial of counselling to reduce children's exposure to environmental tobacco smoke used measures of cotinine concentrations in addition to mothers' reports

Counselled mothers reported significantly greater decreases in exposure to environmental tobacco smoke compared with controls, and children's urine cotinine concentrations decreased slightly for counselled families while increasing substantially for controls

The findings confirm the efficacy of counselling to reduce children's exposure to environmental tobacco smoke 
Preventive Medicine, University of California at San Diego; S Katharine Hammond, Environmental Health Sciences Division, School of Public Health, University of California, Berkeley; Doug Hoffman, Neurochemistry Laboratory, Dartmouth Medical School; Sarah Nordahl Larson, San Diego State University Foundation WIC programme; Brian P Leaderer, Division of Environmental Health Sciences, Yale University School of Medicine.

Contributors: MFH, as principal investigator, had primary responsibility for the study design, administration, quality assurance, planning of statistical analyses, and writing of the manuscript. JMZ, as project coordinator, was responsible for overseeing data collection, intervention delivery, and data preparation and also conducted statistical analyses and contributed to writing the manuscript. GEM collaborated on design of measures, statistical analyses, and editing the manuscript. CRH conducted statistical analyses and assisted with study design and editing the manuscript. JTB conducted urine cotinine analyses and assisted with interpretation of results and editing the manuscript. JP assisted with the study design and editing the manuscript. MFH and JMZ are the guarantors of the paper.

Funding: This research was supported by Grant No 027946 SFP awarded to MFH from the Robert Wood Johnson Foundation Smoke-Free Families Program, and by discretionary funds from the Center for Behavioral Epidemiology and Community Health.

Competing interests: None declared.

1 World Health Organization, Division of Noncommunicable Diseases, Tobacco Free Initiative. International consultation on environmental tobacco smoke (ETS) and child health Consultation report. Geneva: WHO, 1999. www.who.int/toh/TFI/consult.htm (accessed 26 July 2000).

2 Pirkle JL, Flegal KM, Bernert JT, Brody DJ, Etzel RA, Maurer KR. Exposure of the US population to environmental tobacco smoke. The third national health and nutrition examination survey, 1988 to 1991. JAMA 1996;275:1233-40.

3 Centers for Disease Control. State-specific prevalence of cigarette smoking among adults, and children's and adolescents' exposure to environmental tobacco smoke-United States, 1996. MMWR Morb Mortal Wkly Rev 1997;46:1038-43.

4 National Health and Medical Research Council. The health effects of passive smoking. Australia: NHMRC,1997.

5 Physicians for a Smoke-Free Canada. Highlight sheet No 1. Smoking in Canadian homes: Are children at risk? 1999. Available from: www.smokefree.ca/eng home/news press Jun99.htm (accessed 26 July 2000).

6 Jarvis MJ. Children's exposure to passive smoking: survey methodology and monitoring trends. Background paper. 1999. Available from: Tobacco Free Initiative www.who.int/toh/TFI/consult.htm (accessed 7 May 2000).

7 US Department of Health and Human Services (PHS), NIH, US Environmental Protection Agency. Respiratory health effects of passive smoking: lung cancer and other disorders. Washington DC: Office of Research and Development, Office of Air and Radiation, 1993. (NIH publication No 93-3605.)
8 Charlton A. Children and passive smoking: a review. J Fam Pract 1994;38:267-77.

9 Klonoff-Cohen HS, Edelstein SL, Lefkowitz ES, Srinivasan IP, Kaegi D, Chang JC, et al. The effect of passive smoking and tobacco exposure through breast milk on sudden infant death syndrome. JAMA 1995;273:795-8.

10 Adams EK, Melvin C, Merritt R, Worrall B. The costs of envirommental tobacco smoke (ETS): an international review. 1999. Available from: Tobacco Free Initiative www.who.int/toh/TFI/consulthtm (accessed 7 May 2000).

11 Greenberg RA, Strecher VJ, Bauman KE, Boat BW, Fowler MG, Keyes LL, et al. Evaluation of a home-based intervention program to reduce infant passive smoking and lower respiratory illness. J Behav Med 1994;17:27390.

12 Hovell MF, Meltzer SB, Zakarian JM, Wahlgren DR, Emerson JA, Hofstetter CR, et al. Reduction of environmental tobacco smoke exposure among asthmatic children: a controlled trial [published erratum appears in Chest 1995;107:1480]. Chest 1994;106:440-6.

13 Wahlgren DR, Hovell MF, Meltzer SB, Hofstetter CR, Zakarian JM. Reduction of environmental tobacco smoke exposure in asthmatic children: a 2-year follow-up. Chest 1997;111:81-8.

14 Schulte-Hobein B, Schwartz-Bickenbach D, Abt S, Plum C, Nau H. Cigarette smoke exposure and development of infants throughout the first year of life: influence of passive smoking and nursing on cotinine levels in breast milk and infant's urine. Acta Paediatr 1992;81:550-7.

15 Mascola MA, Vunakis HV, Tager IB, Speizer FE, Hanrahan JP. Exposure of young infants to environmental tobacco smoke: breast-feeding among smoking mothers. Am J Public Health 1998;88:893-6.

16 Mattanini MA, Thyer B, eds. Finding solutions to social problems: behavioral strategies for change. Washington DC: American Psychological Association, 1996.

17 Hovell MF, Zakarian JM, Matt GE, Hofstetter CR, Bernert JT, Pirkle J. Decreasing environmental tobacco smoke exposure among low income children: preliminary findings. Tobacco Control 2000;9(suppl 3):iii0-1.

18 Emerson JA, Hovell MF, Meltzer SB, Zakarian JM, Hofstetter CR, Wahlgren DR, et al. The accuracy of environmental tobacco smoke exposure measures among asthmatic children. I Clin Epidemiol $1995 ; 48 \cdot 1251-9$

19 Matt GE, Hovell MF, Zakarian JM, Bernert JT, Pirkle JL, Hammond SK. Measuring second-hand tobacco smoke exposure in babies: the reliability and validity of mother-reports in a sample of low-income families. Health Psychol 2000;19:232-41.

20 Hovell MF, Zakarian JM, Wahlgren DR, Matt GE, Emmons KM. Measurement of environmental tobacco smoke exposure: trials and tribulations. Tobacco Control 2000;9:0-6.

21 Matt GE, Wahlgren DR, Hovell MF, Zakarian JM, Bernert JT, Meltzer SB, et al. Measuring ETS exposure in infants and young children through urine cotinine and memory-based parental reports: empirical findings and discussion. Tobacco Control 1999;8:282-9.

22 Murray DM, O'Connell CM, Schmid LA, Perry CL. Validation of smoking by self-report by adolescents: a re-examination of the bogus pipeline procedures. Addict Behav 1987;12:7-15.

23 Hammond SK, Leaderer BP. A diffusion monitor to measure exposure to passive smoking. Environ Sci Technol 1987;21:494-7.

24 Leaderer BP, Hammond SK. Evaluation of vapor-phase nicotine and respirable suspended particle mass as markers for environmental tobacco smoke. Environ Sci Technol 1991;25:770-7.

25 Diggle PJ, Liang KY, Zeger SL. Analysis of longitudinal data. Oxford: Clarendon Press, 1995.

(Accepted 3 July 2000)

\section{My Cuban experience}

After passing the first part of the MRCP examination, I thought that I would treat myself to an exotic holiday. One of my friends, who is now a consultant psychiatrist, thought that Cuba would be a good place to go. Cuba is a great place to live provided that you have money and that you are not Cuban. For tourists there was always fresh meat and vegetables available. There was no food rationing and we did not have to wait in queues for things like bread. Petrol was expensive and rationed, but we were allowed an unlimited petrol allowance as we had dollars.

Towards the end of our holiday we found ourselves in the capital, Havana. The problem now was trying to get back to our initial resort so that we could catch our flight back home. We weren't really keen on buses or trains as they took so long and so we decided to catch a taxi. Finally one driver agreed to take us. To manage the round trip he had to borrow a friend's petrol ration. As it turned out his English was rather good and so we began chatting. It soon came round to him asking what we did for a living. We both proudly told him that we were doctors in Britain. Without batting an eyelid he pulled out a chest radiograph from behind his seat and asked us to look at it.

"This shows a right pleural effusion with a chest drain," I said.

"Correct," he replied.
"I know," I said. "We told you before we are both doctors."

"Yes," he casually replied, "so am I."

We were most surprised to find out that he wasn't really a taxi driver but a cardiothoracic surgeon and that he was testing our skills. As surgery did not pay well he drove taxis to earn extra cash. We made sure we gave him a nice tip for his trouble when he finally dropped us off.

What have I learnt from this experience? Firstly, never assume anything by a person's profession, and, secondly, do not choose cardiothoracic surgery as a career in Cuba.

A A Palejwala specialist registrar in gastroenterology, Liverpool

We welcome articles of up to 600 words on topics such as A memorable patient, A paper that changed my practice, My most unfortunate mistake, or any other piece conveying instruction, pathos, or humour. If possible the article should be supplied on a disk. Permission is needed from the patient or a relative if an identifiable patient is referred to. We also welcome contributions for "Endpieces," consisting of quotations of up to 80 words (but most are considerably shorter) from any source, ancient or modern, which have appealed to the reader. 